\title{
Distinctive features and response latency: A pilot study
}

\author{
JAMES R. MCINISH AND RONALD S. TIKOFSKY ${ }^{2}$ \\ THE UNIVERSITY OF MICHIGAN
}

Error and latency scores were taken from 12 adults in a forced-choice, consonant-discrimination task. Stimulus items were $C V$ syllables. Each $C V$ contained one of 15 consonants followed by the vowel $/ a /$. Three identical lists of $121 \mathrm{CVs}$ were used. CVs on the three lists were separated by 3,6 , or $12 \mathrm{sec}$, respectively. After each $C V S s$ pressed a button to indicate whether the presented $C V$ was identical to the preceding $C V$. Both error and latency were scored. Results showed that response latency was a reliable measure of consonant discrimination. There was a significant positive correlation between errors and response latency. There was no effect due to interitem delay. Distribution of errors and latencies indicated that description of phonemes in terms of a distinctive feature system is feasible in speech discrimination tasks.

The analysis of speech sounds into bundles of features has a long history in linguistics. The Prague School of linguistics was first to classify speech sounds into ordered sets of specific contrasts of distinctive features (Robbins, 1967). The beginning of experimental studies in this area may be placed at 1951 when Jakobson, Fant, and Halle developed a system that allowed description of any phoneme as a bundle of binary distinctive features. Their system was based on both acoustic and articulatory considerations. Other distinctive feature systems (Miller \& Nicely, 1955; Wickelgren, 1966) were based on conventional phonetic systems and have smaller and less abstract sets of features.

Miller and Nicely employed a set of five features (place, duration, voice, nasality, and affrication). These features were used to describe CV syllables presented to $S$ s in a recognition task having several levels of noise and filtering. They found that with any specific levels of noise and filtering some features were harder to discriminate than others. This weakened discrimination resulted in a confusion among syllables.

Wickelgren employed a set of four features (voice, place, nasality, and openness) and used these in describing strings of CV syllables presented to Ss in a STM study. He reported that ". . . recall of a consonant means recall of a set of features that defines that consonant in memory, and each feature is recalled at least semi-independently of the other features [p. 397]." Here, probability of recall for a specific feature was a function of recall delay. Wickelgren also found that his system described the results somewhat more efficiently than the Miller-Nicely system and much more efficiently than the Halle and Chomsky system, which was a modification of the Jakobson, Fant, and Halle system.

Tikofsky and McInish (1968) employed pairs of CVC syllables in a forced-choice paradigm with 7-year-old Ss. Three of their confirmed hypotheses were: (1) "... as the number of differences in terms of distinctive features increased, the lower the error rate; (2) some distinctive features contribute more to discriminability than others; and (3) within a distinctive feature category, some distinctions are more important than others." Discriminability was judged on the basis of error scores. Not all discriminations could be compared as many were errorless.
The present study sought to: (1) validate response latency as a measure of discriminability in speech perception; (2) replicate Wickelgren's finding of a semi-independent loss of features over time; and (3) replicate the findings of Tikofsky and McInish that discrimination is a function of the number of features in contrast and the specific features in contrast.

\section{METHOD}

Twelve right-handed undergraduates were individually tested in a forced-choice speech discrimination task. The CV syllables used as stimuli were composed of 15 English consonants followed by /a/. These stimulus items were also used by Wickelgren and by Miller and Nicely. Only /z/ of their 16-consonant set was omitted, since it does not occur in the initial position in English words.

Three lists with identical ordering of $121 \mathrm{CV}$ syllables were constructed. Interitem time interval was 3,6 , or $12 \mathrm{sec}$ with one interval for each list. The three lists were constructed so that the consonant members of adjacent $\mathrm{CV}$ syllables were noncontrasting in 58 cases (hereafter called "sames") and contrasting in 62 cases (hereafter called "differents"). A random units table was used to distribute the "sames" and "differents." The two consonants in each "different" contrasted by either one or two Miller-Nicely features. Because of the random distribution, each of the 15 noncontrasting pairings appeared from two to five times. The first and last example of each of the 15 "sames" were selected for analysis. This allowed a check for warm-up effects that could have occurred in the experiment.

Stimulus items were recorded with a flat intonation by a trained speaker in an audiometric room. All items were recorded at a similar intensity level as indicated by the VU-meter on an Ampex 351-2 tape recorder. Ss were seated in a soundproof room and heard the stimuli through an Ampex 622 speaker. No noise or filtration was used to degrade the signal.

The following general instructions were given to each $S$ :

"Please be seated and place your index fingers on these two buttons marked 'Same' and 'Different.' You will hear some sounds of the form, ' $/ \mathrm{pa} /, / \mathrm{ta} /, / \mathrm{da} /$,' etc. After each sound decide whether it was the same as the preceding sound or not. Press the appropriate button. Note that each sound except the first and last will be used in two judgments. Thus, if the beginning of the list is '/pa/, /pa/, /fa/,' you would do nothing after the first $/ \mathrm{pa} /$; press the button marked 'Same' after the second /pa/; and press the button marked 'Different' after / fa/. From all responses you will make, 10 will be randomly selected to be used in determining your pay. [A payoff matrix was shown to $S$.] The number $.45 \mathrm{sec}$ represents an average time to respond. Note that if all of your responses are slower than this, you can make only $\$ .50$ even if all 10 are correct. However, if you respond very quickly, you can miss several and still make good money."

E went into greater detail whenever necessary. Each $S$ was then given 15 practice discriminations from the middle of the first list he was to hear.

Both hand position and list order were balanced. For six Ss "Same" was on the left and for six on the right. Each $S$ in each 
Table 1

Error Scores for Pairs Differing by One and Two MN Features

\begin{tabular}{lccr}
\hline No. features different & Errors & Contrast & Totals \\
\hline One & 49 & 815 & -164 \\
Two & 25 & 1343 & 1368 \\
\hline Totals & 74 & 2158 & 2232 \\
\hline
\end{tabular}

$x^{2}=244.40, p<.01$

group of six received a different order of the three lists. The three lists were presented with a 2 -min pause between each list.

The termination of each $\mathrm{CV}$ released a voice-operated relay that actuated a centisecond timer. The timer was electrically stopped after a response. The response also activated one of two lights allowing $E$ to record both latency and response.

\section{RESULTS AND DISCUSSION ${ }^{3}$}

The first purpose of this experiment, to determine if response latency is a reliable measure of discrimination, was successful. The correlation between error and latency scores for one-feature discriminations was $r=.835$. This correlation implies that latency as well as error data can be used as an indicator of discriminability. In speech discrimination studies many discriminations are errorless. For these errorless discriminations those with shorter latencies can be said to be more discriminable.

Latency scores were analyzed with a three-way, repeated measures ANOVA (Winer, 1962, p. 374). Ss, lists (interitem time intervals), and feature were all significant, $p<.01$. The mean latency was longest for one-feature contrasts $(.466 \mathrm{sec})$ and shortest for "sames" (.397 sec). Two-feature contrasts had a mean latency of $.427 \mathrm{sec}$. Of the three time intervals mean latency was longest for the lists with a 3 -sec separation $(.450 \mathrm{sec})$ and shortest for the list with a 12 -sec separation $(.397 \mathrm{sec})$. The 6-sec separation list had a mean latency of $.35 \mathrm{sec}$.

The error rate was $8.9 \%$ for "sames" and $3.3 \%$ for "differents" and was analyzed with a $\chi^{2}$ test. The obtained difference was significant beyond the .01 level. Table 1 shows that one-feature discriminations had a higher error rate $(5.7 \%)$ than two-feature discriminations (1.8\%). This difference was significant beyond the .01 level. $\mathrm{A} \chi^{2}$ analysis of errors across the three interitem time intervals was not significantly different from chance, $\mathrm{p}>.05$.

The shorter latencies for items separated by $12 \mathrm{sec}$ indicates a probable rehearsal effect. No $S$ volunteered the fact that he rehearsed items, nor were Ss questioned concerning rehearsal. Wickelgren presented lists of CVs for recall. This allowed interference effects within a group of CSs to be recalled and did not allow constant rehearsal of each CV. Thus, the attempt to replicate systematically Wickelgren's STM effect must be judged a failure.

The finding by Tikofsky and McInish of a greater discriminability for pairs differing by more Miller-Nicely features was replicated. Pairs differing by two Miller-Nicely features have shorter response latencies and fewer errors than those differing by only one Miller-Nicely feature.

The present study failed to replicate a second finding by Tikofsky and McInish, the finding that some Miller-Nicely features are more important for discrimination than others. The hypothesis of random error distribution across the five Miller-Nicely features could not be rejected. Both Miller and Nicely and Tikofsky and McInish found a nonrandom distribution of errors across features. However, Miller and Nicely employed both noise and filtration to degrade the signal. The similar finding by Tikofsky and McInish may have been due to
Table 2

Error Scores for each MN Feature Contrast

\begin{tabular}{lccc}
\hline Feature in contrast & Errors & Correct & Totals \\
\hline Voice & 19 & 809 & 828 \\
Affrication & 18 & 738 & 756 \\
Nasality & 11 & 349 & 360 \\
Duration & 10 & 386 & 396 \\
Place & 41 & 1219 & 1260 \\
\hline Totals & 99 & 3501 & 3600 \\
\hline$\chi^{2}=2.42, p>.01$ & & &
\end{tabular}

the age of their Ss, 7 years, or due to the small number of Ss, only four.

A single-factor ANOVA (Winer, 1962, p. 56) showed latency scores were nonrandomly distributed across the 15 different "same" comparisons, $\mathrm{p}<.01$. A $\chi^{2}$ of the distribution of error scores for the 15 different "same" comparisons was not significant, however. It would appear that certain phonemes such as $|\theta|$ require longer processing times for discrimination as measured by response latency, though discrimination, as measured by error scores was the same for all "sames."

\section{CONCLUSIONS}

Previous studies of speech discrimination have used error scores as a measure of discriminability. The present study has established that response latency correlates with error scores and may also be used as an indicator of discriminability. Response latency is a particularly helpful measure for distinguishing discriminability of errorless responses. The failure to find a loss of remembered features as a function of time was interpreted as resulting from rehearsal. Though two-feature discriminations produced shorter latencies and fewer errors than one-feature discriminations, there was no difference as a function of the specific features in contrast. It appears that with a nondegraded signal, discriminability is a function of the number of features in contrast, regardless of which features are contrasted.

\section{REFERENCES}

HALLE, M. On the basis of phonology. In J. A. Fodor and J. J. Katz (Eds.), The structure of language. Englewood-Cliffs: Prentice-Hall, 1964. Pp. 324-333.

JAKOBSON, R., FANT, C., \& HALLE, M. Preliminaries to speech analysis: The distinctive features and their correlates. Cambrdige, Mass.: M.I.T. Press, 1951.

MILLER, G. A., \& NICELY, P. An analysis of perceptual confusions among some English consonants. Journal of the Acoustical Society of America, 1955, 27, 338-352.

ROBBINS, R. H. A short history of linguistics. Bloomington, Ind.: Indiana Press, 1968

TIKOFSKY, R. S., \& McINISH, J. R. Consonant discrimination by seven year olds: A pilot study. Psy chonomic Science, 1967, 10,61-62.

WICKELGREN, W. A. Distinctive features and errors in short-term memory for English consonants. Journal of the Acoustical Society of America, 1966, 39, 388-398.

WINER, B. J. Statistical principles in experimental design. New York: McGraw-Hill, 1962.

\section{NOTES}

1. This research was supported by Grant 1 PO1 HD 01368-04 from the National Institute for Child Health and Human Development.

2. Address: Program in Psycholinguistics, The University of Michigan, 182 Frieze Building, Ann Arbor, Michigan 48104.

3. The complete data analysis is available in Report No. 20 , October 1 , 1968, "Development of language functions," The University of Michigan: Center for Human Growth and Development.

(Accepted for publication February 23, 1969.) 